\title{
Models for Non-isothermal Steady-State Diffusion in Porous Building Materials
}

T. Ficker, Z. Podešvová

Two models for non-isothermal diffusion of water vapour in building materials have been developed and their numerical outputs compared with a standard isothermal approximation.

Keywords: Fick's laws, non-isothermal diffusion, partial pressure profile.

\section{Introduction}

The structure of most building materials of silicate origin consists of mutually interconnected microscopic pores. The diameters of the pores show wide dispersion in their values ranging from nanometers to millimeters. Since the mean free path of water vapour molecules at normal room conditions lies below $1 \mathrm{~nm}$, almost all pores are open for vapour diffusion. However, this is not the only transport mechanism that enables moisture to enter a building material. At higher relative humidity (approx. above $50 \%$ ) intensive capillary condensation occurs on the surface of pores and the pores are subsequently filled with liquid water which can migrate into a material. Liquid transport in pores takes place both by surface diffusion and by capillary flow. However, the purpose of this paper is to deal with diffusion of the gas phase only, i.e., of water vapour, without the liquid transport. This simplification is commonly applied, e.g., within the Glaser condensation model [1], widely used in thermal building technology.

A common practice in thermal building technology is to calculate the vapour diffusion flux and pressure profile $p(x)$ inside building envelopes within an isothermal model, although the envelopes normally experience non-isothermal conditions throughout the year. The temperature of the envelope within the isothermal model is represented by a one-year average for a given climate region (e.g., $10^{\circ} \mathrm{C}$ for Central Europe). Such an approximation has been incorporated into the national thermal standards of various countries [2], [3] and has been in service for many years. Although this procedure might provide satisfactory results for one-year assessment of envelopes, it is clear that that the results for a shorter period can show severe deviations from the experimental data.

\section{Non-isothermal diffusion}

Let us suppose that the building envelope through which the diffusion flux goes is represented by a plain brick wall of thickness $d=44 \mathrm{~cm}$. The wall separates a heated room with a usual environment (surface temperature and relative humidity: $T_{1}=293.15 \mathrm{~K}, \varphi_{1}=60 \% \mathrm{RH}$ ) from an outdoor space $\left(T_{2}=255.15 \mathrm{~K}, \varphi_{2}=84 \% \mathrm{RH}\right)$. The atmospheric pressure of dry air is usually considered to be approximately the same on both sides $\left(p_{\mathrm{a}}=98066.5 \mathrm{~Pa}\right.$ - used in [4]). The atmospheric pressure $p$ consists of partial pressures of water vapor $p_{w}$ and dry air $p_{\mathrm{a}}$

$$
p=p_{\mathrm{w}}+p_{\mathrm{a}}, p_{\mathrm{w}} \ll p_{\mathrm{a}}, p \approx p_{\mathrm{a}} .
$$

Similar relations also hold for mass concentrations as well

$$
c=c_{\mathrm{w}}+c_{\mathrm{a}}, c_{\mathrm{w}} \ll c_{\mathrm{a}}, c \approx c_{\mathrm{a}} .
$$

A reasonable choice [5] for the temperature profile $T(x)$ of a wall is the linear function

$$
T(x)=T_{1}-\frac{T_{1}-T_{2}}{d} x, \quad\left(T_{1}>T_{2}\right) .
$$

Fick's first law for non-isothermal diffusion assumes the following form [12]

$$
q_{\mathrm{w}}=y_{\mathrm{w}}\left(q_{\mathrm{w}}+q_{\mathrm{a}}\right)-c D_{\mathrm{wa}}(T) \nabla y_{\mathrm{w}}, \quad y_{\mathrm{w}}=\frac{c_{\mathrm{w}}}{c}=\frac{c_{\mathrm{w}}}{c_{\mathrm{w}}+c_{\mathrm{a}}}
$$

where $q_{\mathrm{w}}$ and $q_{\mathrm{a}}$ are diffusion fluxes of water vapor and air, respectively, and $D_{\text {wa }}(T)$ is the temperature-dependent diffusivity. The diffusion flow should fulfil the condition of continuous flow

$$
c \frac{\partial y_{\mathrm{w}}}{\partial t}=\nabla q
$$

which is Fick's second law. Assuming unidirectional steady-state diffusion $\left(\partial y_{w} / \partial t=0\right)$ along the $x$-axis and a negligibly small diffusion flow $\left(\boldsymbol{q}_{\mathrm{a}} \rightarrow 0\right.$ ) of heavy air molecules $\left(\mathrm{N}_{2}+\mathrm{O}_{2}+\ldots\right)$ as compared with lighter $\mathrm{H}_{2} \mathrm{O}$ molecules $\left(q_{\mathrm{w}} \gg q_{\mathrm{a}}\right)$, Fick's two equations can be rewritten as follows

$$
\begin{gathered}
q_{\mathrm{w}}=-\frac{c D_{\mathrm{wa}}(T)}{1-y_{\mathrm{w}}(1+r)} \frac{\mathrm{d} y_{\mathrm{w}}}{\mathrm{d} x}, \quad \frac{q_{\mathrm{a}}}{q_{\mathrm{w}}}=r \ll 1, \\
\frac{\mathrm{d}}{\mathrm{d} x} q_{\mathrm{w}}=0 \Rightarrow q_{\mathrm{w}}=\text { const. }
\end{gathered}
$$

with the boundary conditions

$$
y_{\mathrm{w}}(0)=y_{1 \mathrm{w}}, \quad y_{\mathrm{w}}(d)=y_{2 \mathrm{w}} .
$$

Following the work of Schirmer [4] and Krischer [6] the diffusivity of water vapor in the air pores of a material can be expressed as the function of temperature

$D=\frac{k}{\mu} T^{n}, \quad n=1.81, \quad k=8.9718 \times 10^{-10} \mathrm{~m}^{2} \mathrm{~s}^{-1} \mathrm{~K}^{-1.81}$

where $\mu$ is the 'diffusion resistance factor' - a purely material constant corresponding to the wall material. According to the gas law, mass concentration $c$ is a function of pressure and temperature

$c=\frac{p}{R_{\mathrm{wa}} T} \approx \frac{p_{\mathrm{a}}}{R_{\mathrm{a}} T}, \quad R_{\mathrm{a}}=\frac{R}{M_{\mathrm{a}}} \approx 297 \mathrm{~J} \mathrm{~kg}^{-1} \mathrm{~K}^{-1}$,

$R=8.31 \mathrm{~J} \mathrm{~mol}^{-1} \mathrm{~K}^{-1}$.

From Eqs. (3) - (10) it follows 


$$
\frac{p_{\mathrm{a}} k}{R_{\mathrm{a}} \mu} \int_{y_{\mathrm{lw}}}^{y_{\mathrm{w}}(x)} \frac{\mathrm{d} y_{\mathrm{w}}}{1-y_{1 \mathrm{w}}(1+r)}=-q_{\mathrm{w}} \int_{0}^{x}\left[T_{1}+\frac{T_{1}-T_{2}}{d} x\right]^{1-n} \mathrm{~d} x .
$$

Inserting the second boundary condition (8) into (11) we obtain the diffusion flux

$q_{\mathrm{w}}=\frac{p_{\mathrm{a}} k(2-n)}{R_{\mathrm{a}} d \mu(1+r)} \cdot \frac{T_{1}-T_{2}}{T_{1}^{2-n}-T_{2}^{2-n}} \cdot \ln \left[\frac{1-y_{2 \mathrm{w}}(1+r)}{1-y_{1 \mathrm{w}}(1+r)}\right]$,

$n=1.81$

which, together with (11), gives the vapor profile $y_{\mathrm{w}}(x)$

$$
\begin{aligned}
y_{\mathrm{w}}(x)= & \frac{1}{1+r}\left\{1-\left[1-y_{1 \mathrm{w}}(1+r)\right] .\right. \\
& \left.\cdot\left[\frac{1-y_{2 \mathrm{w}}(1+r)}{1-y_{1 \mathrm{w}}(1+r)}\right] \frac{T_{1}^{2-n}-\left(T_{1}-\frac{T_{1}-T_{2}}{d} x\right)^{2-n}}{T_{1}^{2-n}-T_{2}^{2-n}}\right\}, n=1.81
\end{aligned}
$$

Taking into account the diffusion through an immobilized air layer (DIAL model), i.e., $q_{\mathrm{a}} \rightarrow 0(r \rightarrow 0)$, relations (12), (13) can be simplified

$q_{\mathrm{w}}^{*}=\frac{0.19 p_{\mathrm{a}} k}{R_{\mathrm{a}} d \mu} \frac{T_{1}-T_{2}}{T_{1}^{0.19}-T_{2}^{0.19}} \cdot \ln \left[\frac{1-y_{2 \mathrm{w}}}{1-y_{1 \mathrm{w}}}\right]$,

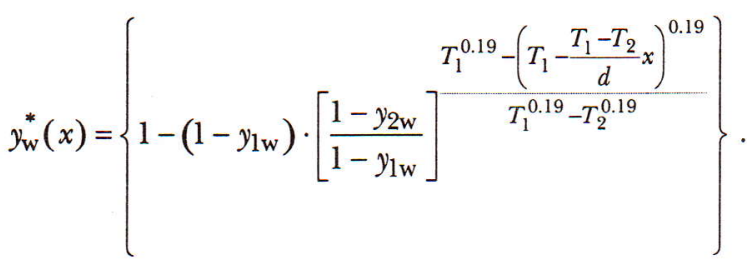

Relation (14) may be formally rewritten as follows

$$
q_{\mathrm{w}}^{*}=\frac{\ln \left[\frac{1-y_{2 \mathrm{w}}}{1-y_{1 \mathrm{w}}}\right]}{R_{\mathrm{eff}}^{*}}, \quad R_{\mathrm{eff}}^{*}=\frac{d}{D_{\mathrm{eff}}^{*}}\left[\mathrm{~kg}^{-1} \mathrm{~m}^{2} \mathrm{~s}\right],
$$

where

$$
\begin{aligned}
D_{\text {eff }}^{*} & =\frac{0.19 k p_{\mathrm{a}}}{\mu R_{\mathrm{a}}} \cdot \frac{T_{1}-T_{2}}{T_{1}^{2-n}-T_{2}^{2-n}}= \\
& =\frac{5.629 \times 10^{-8}}{\mu} \cdot \frac{T_{1}-T_{2}}{T_{1}^{0.19}-T_{2}^{0.19}}\left[\mathrm{~kg} \mathrm{~m}^{-1} \mathrm{~s}^{-1}\right] .
\end{aligned}
$$

Since $y_{1 w} \ll 1$ and $y_{2 w} \ll 1$, further simplification can be performed

$$
\ln \left[\frac{1-y_{2 \mathrm{w}}}{1-y_{1 \mathrm{w}}}\right] \approx y_{1 \mathrm{w}}-y_{2 \mathrm{w}}, \quad q_{\mathrm{w}}^{*} \approx \frac{y_{1 \mathrm{w}}-y_{2 \mathrm{w}}}{R_{\mathrm{eff}}^{*}}\left[\mathrm{~kg} \mathrm{~m}^{-2} \mathrm{~s}^{-1}\right] .
$$

\section{DRAL model}

Relations (14) - (17) hold within the framework of the DIAL approximation, when the air layer embedded in a porous material is only slightly perturbed by the diffusion of water vapor molecules that possess smaller mass and much lower concentration than those of air. It seems to be natural that not only the pressure of dry air remains constant but also the concentrations of dry and wet air vary only slightly across the wall. This can be nicely illustrated when the concentration ratios are calculated for a particular case, e.g., for the internal and external conditions defined at the beginning of the previous Section

$$
\begin{aligned}
& c_{\mathrm{w}}^{\text {inner }} / c_{\mathrm{w}}^{\text {outer }}=16.23, \\
& c_{\mathrm{a}}^{\text {inner }} / c_{\mathrm{a}}^{\text {outer }}=0.870, \\
& c^{\text {inner }} / c^{\text {outer }}=0.883
\end{aligned}
$$

From (18) it can be seen that the variations of air concentrations $c_{\mathrm{a}}, c$ across the wall are negligibly small and, thus, the profiles $c_{\mathrm{a}}(x), c(x)$ may be considered as approximately horizontal, i.e., constant for common climatic conditions. This does not hold at all for water vapor whose concentration varies considerably and, thus, its profile shows clear functional dependence on $x$

$$
\begin{aligned}
& c_{\mathrm{w}}=f(x), \quad c_{\mathrm{a}} \approx \text { const. }, \\
& c \approx \text { const. }, \quad c_{\mathrm{w}}(x) \ll c_{\mathrm{a}} .
\end{aligned}
$$

If these relations are included into Fick's Eq.(6), we can obtain a more simplified transport equation

$$
\begin{aligned}
& q_{\mathrm{d}}=-D_{\mathrm{wa}}(T) \frac{\mathrm{d} c_{\mathrm{w}}\left(T, p_{\mathrm{w}}\right)}{\mathrm{d} x}, \quad 1-y_{\mathrm{w}} \approx 1, \\
& r \approx 0, \quad c \approx \text { const. }
\end{aligned}
$$

An analogous transport equation holds for non-isothermal diffusion of a gas in a solid compact body, so present approximation might be termed as Diffusion through a 'Rigid' Air Layer (DRAL model). At first sight this approximation might seem rather unrealistic, but the final account of all physical factors and their approximate behavior leads to such a conclusion. Eq. (20) is quite analogous to those presented in technical literature for cases when the total concentration is constant (see e.g. Eq. 16.2-3 in [7]). The assumption $c=$ const. does not necessarily mean the condition for the isothermal state. Nearly constant total concentration $c$ can be expected not only with non-isothermal diffusion of a gas in a solid compact body which does not contain any air pores but also in solid materials containing closed pores (cavities) filled with air. The diffusion flux in such materials goes either through the airless solid structures whose concentration (density) is almost unaffected by temperature and through voids with a constant air content (constant concentration), provided the walls of the voids are hardly penetrable for heavy air molecules in contrast to lighter water molecules. Foam building materials such as foam polyethylene approach this type of material. It seems probable that the DRAL model might be more applicable to such materials. However, it is necessary to stress that if a strong non-isothermal state causes essential variations in the total concentration profile, i.e., $c=\mathrm{f}(x)$, the DRAL model will fail to determine a realistic diffusion flux. Briefly, the transport equation (20) should enable the diffusion flux of water 
vapor in various materials to be approximated only under usual climatic conditions, since such conditions represent a weakly non-isothermal state which does not essentially disturb the total concentration profile. Nevertheless, for a highly non-isothermal state, the DRAL model can yield correct results only with quite special materials. Numerical comparison of the results obtained by various models is presented in Section 5 .

Let us continue determining the solution of differential equation (20). First, it is necessary to specify the complete set of Fick's equations within the DRAL approximation

$q_{\mathrm{w}}=-\frac{D}{R_{\mathrm{w}}} \frac{\mathrm{d}}{\mathrm{d} x}\left(\frac{p_{\mathrm{w}}(x)}{T(x)}\right), c_{\mathrm{w}}=\frac{p_{\mathrm{w}}}{R_{\mathrm{w}} T}, R_{\mathrm{w}}=462 \mathrm{~J} \mathrm{~kg}^{-1} \mathrm{~K}^{-1}$,

$\frac{\mathrm{d}}{\mathrm{d} x}\left[\frac{k}{\mu R_{\mathrm{w}}} T^{n}(x) \frac{\mathrm{d}}{\mathrm{d} x}\left(\frac{p_{\mathrm{w}}(x)}{T(x)}\right)\right]=0, n=1.81$

and the boundary conditions belonging to a non-isothermal wall of thickness $d$

$$
\frac{p_{\mathrm{w}}(0)}{T(0)}=\frac{p_{1 \mathrm{w}}}{T_{1}}, \quad \frac{p_{\mathrm{w}}(d)}{T(d)}=\frac{p_{2 \mathrm{w}}}{T_{2}} .
$$

Since the non-linear temperature profile $T(x)$ appears in common walls only under special conditions [10], a linear profile is assumed here as well

$$
T(x)=T_{1}-\frac{T_{1}-T_{2}}{d} x=a-b x .
$$

Inserting (24) into Fick's equations (21), (22) and taking into account the first boundary condition (23), the corresponding solution can be found

$$
\frac{k}{\mu R_{\mathrm{w}}}(a-b x)^{n} \frac{\mathrm{d}}{\mathrm{d} x}\left(\frac{p_{\mathrm{w}}}{T}\right)=-q_{\mathrm{d}}=\text { const. },
$$

$$
\begin{gathered}
\int_{p_{1 \mathrm{w}} / \mathrm{T}_{1}}^{p_{\mathrm{w}}(x) / T(x)} \mathrm{d}\left(\frac{p_{\mathrm{w}}}{T}\right)=\int_{0}^{x}-\frac{q_{\mathrm{d}} R_{\mathrm{w}} \mu}{k}(a-b x)^{-n} \mathrm{~d} x, \\
q_{\mathrm{w}}=\frac{\left(\frac{p_{1 \mathrm{w}}}{T_{1}}-\frac{p_{2 \mathrm{w}}}{T_{2}}\right) k b(1-n)}{\mu R_{\mathrm{w}}\left[a^{1-n}-(a-b x)^{1-n}\right]} .
\end{gathered}
$$

Inserting the second boundary condition (23) into (27), we can express the steady-state diffusion flux $q_{\mathrm{w}}$

$$
q_{\mathrm{w}}=\frac{\left(\frac{p_{1 \mathrm{w}}}{T_{1}}-\frac{p_{\mathrm{w}}(x)}{T(x)}\right) k b(1-n)}{\mu R_{\mathrm{w}}\left[a^{1-n}-(a-b d)^{1-n}\right]}
$$

which goes through a non-isothermal wall with a linear temperature profile (24). The symbols $a, b$ in (28) can be specified using (24)

$q_{\mathrm{w}}=\frac{k(1-n)}{\mu R_{\mathrm{w}} d} \frac{\left(\frac{p_{1 \mathrm{w}}}{T_{1}}-\frac{p_{2 \mathrm{w}}}{T_{2}}\right)\left(T_{1}-T_{2}\right)}{T_{1}^{1-n}-T_{2}^{1-n}}, \quad n=1.81$

Relation (29) can be rearranged and the effective diffusion resistance $R_{\text {eff }}$ and effective coefficient $D_{\text {eff }}$ may be introduced

$$
\begin{aligned}
& q_{\mathrm{w}}=\frac{c_{1 \mathrm{w}}-c_{2 \mathrm{w}}}{R_{\text {eff }}}\left[\mathrm{kg} \mathrm{m}^{-2} \mathrm{~s}^{-1}\right], \\
& R_{\text {eff }}=\frac{d}{D_{\text {eff }}}\left[\mathrm{m}^{-1} \mathrm{~s}\right], \\
& D_{\text {eff }}=\frac{k(n-1)\left(T_{1}-T_{2}\right)}{\mu\left(T_{2}^{1-n}-T_{1}^{1-n}\right)}\left[\mathrm{m}^{2} \mathrm{~s}^{-1}\right]
\end{aligned}
$$

where

$c_{1 \mathrm{w}}=\frac{p_{1 \mathrm{w}}}{R_{\mathrm{w}} T_{1}} \quad\left[\mathrm{~kg} \mathrm{~m}^{-3}\right], \quad c_{2 \mathrm{w}}=\frac{p_{2 \mathrm{w}}}{R_{\mathrm{w}} T_{2}} \quad\left[\mathrm{~kg} \mathrm{~m}^{-3}\right]$.

By means of relations (30) the non-isothermal diffusion flux $q_{w}$ expressed within the DRAL approximation can be easily calculated.

For completeness, the partial pressure profile $p_{w}(x)$ inside the wall should be presented. Functions $p_{\mathrm{w}}(x)$ and $c_{\mathrm{w}}(x)$ are given by Eqs. (27) and (28)

$p_{\mathrm{w}}(x)=\left(T_{1}-\frac{T_{1}-T_{2}}{d} x\right)$.
$\left[\frac{p_{1 \mathrm{w}}}{T_{1}}-\left(\frac{p_{1 \mathrm{w}}}{T_{1}}-\frac{p_{2 \mathrm{w}}}{T_{2}}\right) \frac{T_{1}^{1-n}-\left(T_{1}-\frac{T_{1}-T_{2}}{d} x\right)^{1-n}}{T_{1}^{1-n}-T_{2}^{1-n}}\right]$,

$c_{\mathrm{w}}(x)=\frac{p_{1 \mathrm{w}}}{R_{\mathrm{w}} T_{1}}-\left(\frac{p_{1 \mathrm{w}}}{R_{\mathrm{w}} T_{1}}-\frac{p_{2 \mathrm{w}}}{R_{\mathrm{w}} T_{2}}\right)^{T_{1}^{1-n}-\left(T_{1}-\frac{T_{1}-T_{2}}{d} x\right)^{1-n}}{T_{1}^{1-n}-T_{2}^{1-n}}^{1-n}$.

For $n=1.81$ the profiles $p_{\mathrm{w}}(x)$ and $c_{\mathrm{w}}(x)$ will read

$p_{\mathrm{w}}(x)=\left(T_{1}-\frac{T_{1}-T_{2}}{d} x\right)$.

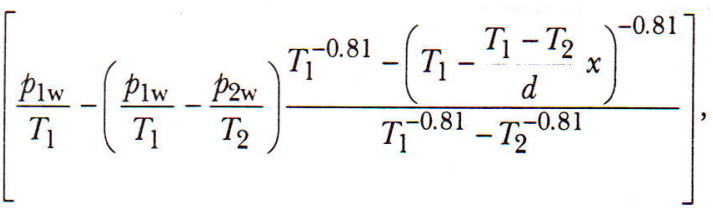

$c_{\mathrm{w}}(x)=c_{1 \mathrm{w}}-\left(c_{1 \mathrm{w}}-c_{2 \mathrm{w}}\right) \frac{T_{1}^{-0.81}-\left(T_{1}-\frac{T_{1}-T_{2}}{d} x\right)^{-0.81}}{T_{1}^{-0.81}-T_{2}^{-0.81}}$.

At first sight it is obvious that the $p_{w}(x)$ and $c_{w}(x)$ profiles are not linear. Nevertheless, for usual temperature and partial pressure differences between outdoor and indoor spaces in the Central European climatic region the graphs of $p_{\mathrm{w}}(x)$ and $c_{w}(x)$ will closely follow linear behaviour, as can be easily verified.

\section{IM-TDR and IM-TIR models}

Glaser's standard condensation model [1] is based on isothermal diffusion, i.e., the temperature of a wall is considered to be a constant $T_{\mathrm{m}}$ and equal to the mean value of the surface temperatures

$$
T_{\mathrm{m}}=\frac{T_{1}+T_{2}}{2} .
$$

Fick's equations for diffusion in an isothermal structure can be obtained from (21) and (22) after inserting $T=T_{\mathrm{m}}$ 


$$
q_{\mathrm{d}}=-\frac{D}{R_{\mathrm{w}} T_{\mathrm{m}}} \cdot \frac{\mathrm{d} p_{\mathrm{w}}}{\mathrm{d} x}, \frac{\mathrm{d} q_{\mathrm{d}}}{\mathrm{d} x}=0
$$

where

$$
D=\frac{k}{\mu} T_{\mathrm{m}}^{n}, n=1.81 .
$$

Using the following boundary conditions

$$
p_{\mathrm{w}}(0)=p_{1 \mathrm{w}}, \quad p_{\mathrm{w}}(d)=p_{2 \mathrm{w}}
$$

the solution of (36) can be found easily

$$
\begin{gathered}
q_{\mathrm{d}}=\frac{p_{1 \mathrm{w}}-p_{2 \mathrm{w}}}{R_{\mathrm{d}}}, \quad R_{\mathrm{d}}=\frac{\mu d}{\delta}, \quad \delta=\frac{k T_{\mathrm{m}}^{n-1}}{R_{\mathrm{w}}}, \quad n=1.81 \\
p(x)=p_{1 \mathrm{w}}-\frac{p_{1 \mathrm{w}}-p_{2 \mathrm{w}}}{d} x .
\end{gathered}
$$

As can be seen, the pressure profile $p(x)$ is a linear function of $x$ in contrast to non-isothermal profiles (15) and (34), which are non-linear. In spite of the fact that Fick's Eqs. (36) hold exactly for isothermal structures only, i.e., for constant temperature, the thermal resistance $R_{\mathrm{d}}$ is actually temperature dependent $R_{\mathrm{d}}\left(T_{\mathrm{m}}\right)$. Such a model may be termed as an 'isothermal model with temperature dependent resistance', i.e., IM-TDR.

Nevertheless, in civil engineering practice Fick's isothermal equations are combined with thermal resistance that is not temperature dependent, because the average temperature is fixed to the one-year average, i.e., $T_{\mathrm{m}}=283.15 \mathrm{~K}$, regardless of the actual value $T_{\mathrm{m}}$ of a particular structure. Such a model may be called an "isothermal model with temperature independent resistance', i.e., IM-TIR.

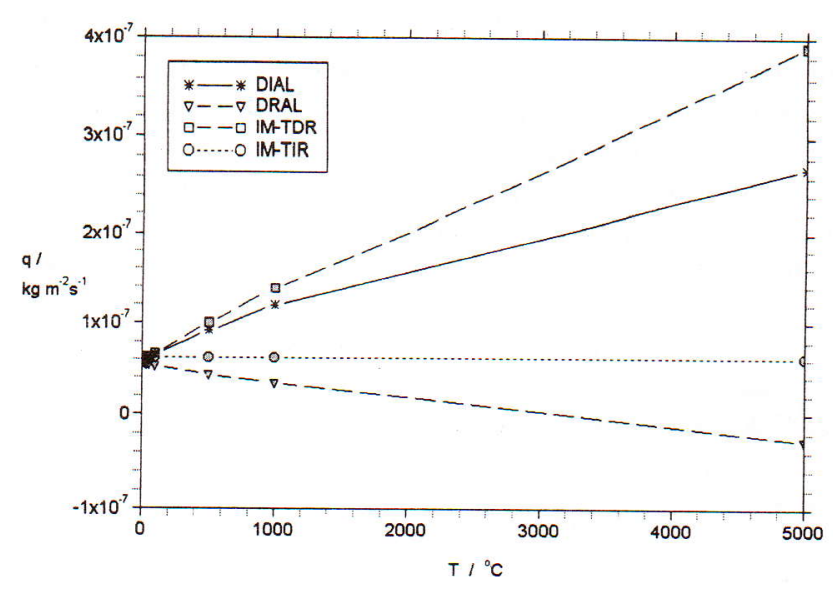

Fig. 1: Diffusion fluxes in dependence on temperature

\section{Results and conclusions}

In order to analyse the behaviour of all the models discussed, their results for the structure given at the beginning of Chapter 2 are presented in Fig. 1 and Table 1. The calculations were done under the assumption that the external partial pressure of water vapour remained constant while the external temperature was successively increasing, i.e., the external relative humidity was decreasing. Such conditions enable us to study the influence of temperature difference $\Delta T=T_{1}-T_{2}$ on the numerical compatibility of the models.

Table 1: Diffusion fluxes through the brick wall $(\mu=9)$ separating external space $\left(\varphi=84 \% \mathrm{R} . \mathrm{H} ., T_{2}=255.18 \mathrm{~K}, p_{2 \mathrm{w}}=105 \mathrm{~Pa}\right)$ and an internal room with increasing temperature $\left(20^{\circ} \mathrm{C}-5000^{\circ} \mathrm{C}\right)$

\begin{tabular}{|l|c|c|c|c|c|c|c|}
\hline \multicolumn{1}{|c|}{ Quantity } & $\begin{array}{c}293.15 \mathrm{~K} \\
\left(20^{\circ} \mathrm{C}\right)\end{array}$ & $\begin{array}{c}303.15 \mathrm{~K} \\
\left(30^{\circ} \mathrm{C}\right)\end{array}$ & $\begin{array}{c}323.15 \mathrm{~K} \\
\left(50^{\circ} \mathrm{C}\right)\end{array}$ & $\begin{array}{c}373.15 \mathrm{~K} \\
\left(100^{\circ} \mathrm{C}\right)\end{array}$ & $\begin{array}{c}773.15 \mathrm{~K} \\
\left(500{ }^{\circ} \mathrm{C}\right)\end{array}$ & $\begin{array}{c}1273.15 \mathrm{~K} \\
\left(1000^{\circ} \mathrm{C}\right)\end{array}$ & $\begin{array}{c}5273.15 \mathrm{~K} \\
\left(5000^{\circ} \mathrm{C}\right)\end{array}$ \\
\hline$p_{\mathrm{w}}[\mathrm{Pa}]$ & 1402.2 & 1402.2 & 1402.2 & 1402.2 & 1402.2 & 1402.2 & 1402.2 \\
\hline$c_{\mathrm{w}} \times 10^{3}\left[\mathrm{~kg} \mathrm{~m}^{-3}\right]$ & 10.350 & 10.000 & 9.392 & 8.1340 & 3.9300 & 2.3800 & 5.7600 \\
\hline$y_{\mathrm{w}} \times 10^{3}$ & 9.1 & 9.1 & 9.1 & 9.1 & 9.1 & 9.1 & 9.1 \\
\hline $\begin{array}{l}\text { IM-TIR } \\
R_{\mathrm{d}} \times 10^{-9}\left[\mathrm{~m} \mathrm{~s}^{-1}\right]\end{array}$ & 20.956 & 20.956 & 20.956 & 20.956 & 20.956 & 20.956 & 20.956 \\
\hline $\begin{array}{l}\text { IM-TDR } \\
R_{\mathrm{d}} \times 10^{-9}\left[\mathrm{~m} \mathrm{~s}^{-1}\right]\end{array}$ & 21.61 & 21.61 & 21.29 & 19.35 & 12.98 & 9.42 & 3.32 \\
\hline $\begin{array}{l}\text { DIAL } \\
R_{\text {eff }}^{*} \times 10^{-4} \\
{\left[\mathrm{~kg} \mathrm{~m} \mathrm{~m}^{-1} \mathrm{~s}^{-1}\right]}\end{array}$ & 14.18 & 13.98 & 13.61 & 12.8 & 9.13 & 7.07 & 3.13 \\
\hline $\begin{array}{l}\text { DRAL } \\
R_{\mathrm{eff}} \times 10^{-4}\left[\mathrm{~m}^{2} \mathrm{~s}^{-1}\right]\end{array}$ & 17.13 & 16.62 & 15.68 & 13.75 & 7.00 & 4.38 & 1.15 \\
\hline $\begin{array}{l}\text { IM-TIR } \\
q \times 10^{8}\left[\mathrm{~kg} \mathrm{~m}^{-2} \mathrm{~s}^{-1}\right]\end{array}$ & 6.19 & 6.19 & 6.19 & 6.19 & 6.19 & 6.19 & 6.19 \\
\hline $\begin{array}{l}\text { IM-TDR } \\
q \times 10^{8}\left[\mathrm{~kg} \mathrm{~m}^{-2} \mathrm{~s}^{-1}\right]\end{array}$ & 6.00 & 6.00 & 6.10 & 6.70 & 10.00 & 13.77 & 39.07 \\
\hline $\begin{array}{l}\text { DIAL } \\
q \times 10^{8}\left[\mathrm{~kg} \mathrm{~m}^{-2} \mathrm{~s}^{-1}\right]\end{array}$ & 5.93 & 6.02 & 6.18 & 6.57 & 9.21 & 11.9 & 26.87 \\
\hline $\begin{array}{l}\text { DRAL } \\
q \times 10^{8}\left[\mathrm{~kg} \mathrm{~m}^{-2} \mathrm{~s}^{-1}\right]\end{array}$ & 5.48 & 5.42 & 5.27 & 4.34 & 3.40 & -2.83 \\
\hline
\end{tabular}


Table 1 and Fig. 1 show that at 'small' temperature differences $(\Delta T<40 \mathrm{~K})$ the heat fluxes of all four models differ only by a few percent and, thus, under such 'quasi-isothermal' conditions all the models give nearly identical results. Since the temperature difference $\Delta T$ in the Central European climatic region does not usually exceed fifty Kelvin during a year, all the models seem to be applicable within civil engineering practice.

Nevertheless, if strongly non-isothermal conditions are established $(\Delta T \gg 40 \mathrm{~K})$, it is necessary to distinguish carefully between computational models. While the IM-TIR scheme is not applicable at all under such conditions, the applicability of the remaining three models will depend on the material structure. For materials with macroscopic open pores filled with air (such as silicate building materials or mineral wool) the most convenient models seem to be DIAL and IM-TDR, the first of which should be given priority in practical calculations. The applicability of the DRAL model under strongly non-isothermal conditions is more problematic since it requires a constant total concentration profile to be established, which is fulfilled only with special materials.

\section{References}

[1] Glaser, H.: Graphisches Verfahren zur Untersuchung von Diffusionsvorgängen. Kältetechnik, 1959, Vol. 11, No. 10, p. 345-349.

[2] Czech Thermal Standard: ČSN 73 0540, Český normalizační institut, Praha, 1994.
[3] German Thermal Standard: DIN 4108, Deutsches Institut für Normung, Berlin, 1999.

[4] Schirmer, R.: Diffusionszahl von Wasserdampf-Luftgemischen und die Verdampfungsgeschwindigkeit. Z. VDI-Beil., Verfahrenstechnik, 1938, Vol. 6, p. 170-177.

[5] Ficker, T., Myslín, J., Podešvová, Z.: Non-linear temperature profiles. Acta Polytechnica, 2001, Vol. 41, No. 6, p. 66-68.

[6] Krischer, O.: Grundgesetze der Feuchtigkeitsbewegung in Trockengütern. Kapillarwasserbewegung und Dampfdiffusion. Z. VDI - Beih. Verfahrenstechnik, 1938, Vol. 82, p. 373-380.

[7] Bird, R. B., Stewart, W. E., Lightfoot, E. N.: Transport Phenomena. New York: J. Wiley \& Sons, 1965 (in Czech translation)

Assoc. Prof. RNDr. Tomáš Ficker, DrSc.

Department of Physics

phone: +420541 147661

e-mail: fyfic@fce.vutbr.cz

Ing. Zdenka Podešvová

Department of Building Structures

Faculty of Civil Engineering

University of Technology

Žižkova 17

66237 Brno, Czech Republic 